\title{
Strates
}

STRATES Matériaux pour la recherche en sciences sociales

$12 \mid 2006$

Nouvelles tensions impériales et recompositions en Europe centrale, orientale, et CEI

\section{Retour sur les acteurs : de Solidarité à la Table ronde de 1989}

\section{OpenEdition}

\section{Journals}

Édition électronique

URL : http://journals.openedition.org/strates/1652

DOI : $10.4000 /$ strates. 1652

ISSN : $1777-5442$

Éditeur

Laboratoire Ladyss

Édition imprimée

Date de publication : 31 décembre 2006

ISSN : 0768-8067

\section{Référence électronique}

«Retour sur les acteurs : de Solidarité à la Table ronde de 1989 », Strates [En ligne], 12 | 2006, mis en ligne le 19 juillet 2007, consulté le 08 septembre 2020. URL : http://journals.openedition.org/strates/ 1652 ; DOI : https://doi.org/10.4000/strates.1652

Ce document a été généré automatiquement le 8 septembre 2020

Tous droits réservés 


\section{Retour sur les acteurs : de Solidarité à la Table ronde de 1989}

1 Compte-rendu d'un débat tenu lors de la Convention régionale de l'Association pour l'étude des nationalités à Varsovie en juillet 2004 en présence de Stanislas Ciosek, ancien ambassadeur polonais à Moscou et Janush Reykowsky, participant aux négociations de 1989. Propos retranscrits par Wanda Dressler.

2 Selon l'ambassadeur polonais à Moscou, Stanislas Ciosek, un des négociateurs avec l'Église, "le mouvement Solidarité fut inattendu et il sortit spontanément des mouvements de grève de Gdansk des années soixante-dix. Il est issu d'un groupe de travailleurs des chantiers soutenu par un club d'intellectuels dont Mazowiecki était président. Avec 21 membres, ce dernier fondit le mouvement Solidarité. Le gouvernement cherchait des experts pour négocier le conflit. Il cessa en fait de négocier avec les travailleurs. Il était inattendu que le gouvernement accepte cette organisation qui provoqua une telle mobilisation et compta trois puis six millions de membres en quelques mois. Ce fut un mouvement démocratique avec une structure interne et des meetings. On ne pouvait pas prévoir ce qui allait se passer, ni comment ce mouvement allait se développer. Le gouvernement fut vite effrayé par la variété d'expressions des revendications autonomes. En décembre 1981, il eut peur de la guerre civile et décréta la loi martiale. Les membres de Solidarité furent arrêtés, dont Lech Walesa, avec 10000 personnes. Cette vague répressive eut pour effet de casser le mouvement. »

3 «Une première période de trois ans à partir de la loi martiale fut relativement calme. Le général reconnut que, sans un support minimum de la société, il ne pouvait ni gouverner, ni réformer. La situation était révolutionnaire. Des contacts informels réguliers étaient établis avec Moscou. Cette situation dura jusqu'en 1988. Solidarité ne comptait plus qu'un $1 / 2$ million de membres à cette date. L'opposition faiblit. Le pouvoir essaya de négocier la paix sociale. L'Église fut sollicitée pour jouer un rôle de médiation et d'organisation d'une table ronde. Un meeting fut organisé avec le premier secrétaire du parti, responsable des négociations et conseiller du président. Il n'y eut pas de contrat ni d'agrément important. Il s'agissait seulement d'attendre et d'éviter l'usage de la force. En 1988, le gouvernement eut peur que le mouvement n'évolue de la 
même façon qu'en 1981. Tout se fit donc sous le manteau, les deux camps étant affaiblis. »

4 «On établit un contrat politique général, mais pas de contrat avec les militaires. Le pouvoir a surestimé Solidarité en 1981. Il n'a pas pris la réelle dimension des choses et n'aurait pas dû décréter la loi martiale mais négocier la paix entre partenaires égaux. Les révolutionnaires non plus n'ont pas pris la mesure des événements. Le support dont ils bénéficiaient ne suffisait pas pour comprendre ce qui se passait au sein des forces non gouvernementales de 1968 à 1989 et évaluer les forces de changement requises pour développer la démocratie et le marché. Les entreprises ressentaient un profond besoin de changement, un nouveau sens des responsabilités. Nous ne voulions pas prendre le pouvoir mais le partager et avoir de meilleurs gouvernants. Les élites étaient épuisées, en attente de changements. L'Église a joué un rôle équilibrant et stabilisateur. Nous comprenons l'Église, sa hiérarchie. Notre confiance en elle et dans ses orientations a une grande influence sur nous. »

5 «Le contenu de l'Accord, pour moi, c'était du socialisme naï. On a décrit un gouvernement de justice sociale. On a signé de belles choses, mais rien sur l'économie de marché ne fut mentionné. On ne fit pas de condamnation. Le gouvernement rencontra les partenaires européens. Cela représente l'expérience la plus importante des années 1989-1990, mais le plus difficile était de faire usage de cette expérience. Du fait de notre faible encadrement, personne ne savait comment faire tourner les affaires de l'État. Geremek n'eut pas assez de ressources pour la formation de cadres. Après 1989, on assista ainsi à la dispersion des membres de Solidarité mais non à la formation de partis politiques. »

6 Janush Reykorsky a demandé à participer aux négociations avec son collègue Geremek pour aller vers l'économie de marché et vers un ordre démocratique, après avoir totalement perdu confiance dans le socialisme. «Une partie de l'élite était frustrée et bloquée par les privilèges. La situation de la Pologne commença à changer avec la Perestroika. On craignait que Michael Gorbatchev n'impose ses solutions. Des négociations avec Solidarité étaient inévitables pour développer un consensus politique. On ne savait comment le rendre possible sous Geremek. Des garanties de changement furent données par Gorbatchev pour réaliser une structure de pouvoir effective, éviter les côtés émotionnels et dialoguer avec les gens en grève. »

7 «Les négociations eurent lieu entre partenaires égaux tournés vers le futur. Chaque jour, des comptes-rendus étaient faits, rituellement sous le contrôle de la société. Il était crucial qu'il n'y ait pas de secret. Le mouvement était très idéaliste et n'a pas toujours été capable de mettre en œuvre un changement politique. Une telle issue était impensable du temps de Brejnev. »

\section{RÉSUMÉS}

Ce texte retraduit les propos de deux acteurs et observateurs des négociations de la Table ronde de 1989 qui jugent le mouvement Solidarité, le rôle du 13 décembre 1981 et le contenu des 
négociations avec un certain recul historique et une distance critique qui leur permettent de dire que le pouvoir d'alors a surestimé le rôle et la puissance d'un mouvement qui n'a pas pu ni su s'organiser de façon durable dans la légalité ni dans la clandestinité pour former ainsi des cadres solides susceptibles d'assurer durablement les tâches du pouvoir qui lui incombait.

Back to the actors: from Solidarity to the 1988 Round Table

This text relates the discussions of two actors and observers of the 1988 Round Table. They give their opinion on the Solidarity movement, the role of the 13/12/1981, and the negotiations content with a certain amount of historical perspective and a critic's distance. This allows them to say that the powers at the time overestimated the role and strength of a movement which was not been able to organise itself in a sustainable way either when underground or when made legal. It was thus unable to train the strong leadership needed to cope in a lasting manner with the tasks brought about by the exercise of power. 